\title{
Cutaneous Metastasis of Signet Ring Cell Carcinoma: An Unusual Case
} Report

\author{
Shekhar N Pradhan ${ }^{1}$, Asha S Khade ${ }^{1}$, Umesh Y Bhoi ${ }^{1}$, Sudarshan Gaurkar ${ }^{1}$, Liza Borah ${ }^{1}$ and Malika \\ Sharma ${ }^{1, *}$ \\ ${ }^{1}$ Department of Dermatology, Govt. Medical College, Miraj, Maharashtra, India \\ "Corresponding author: Department of Dermatology, Govt. Medical College, Miraj, Maharashtra, India. Email: malika96sharma@gmail.com
}

Received 2021 February 28; Revised 2021 August 28; Accepted 2021 August 28.

\begin{abstract}
Introduction: Signet ring cell carcinoma is a rare form of highly malignant adenocarcinoma, with the prevalence rate of $<1 \%$. The most common site of the primary tumor is the stomach, and the secondary sites are the breast, gall bladder, urinary bladder, and pancreas. Moreover, the common metastasis sites of signet ring cell carcinomas are the lung and the liver. Skin metastasis is extremely rare, with the prevalence rate of $0.3 \%$. Signet ring cell carcinomas are usually diagnosed during the late stages of the disease; hence, the tumors spread more aggressively than non-signet ring cell types, thereby making treatment challenging.

Case presentation: We report a 30-year-old male with cutaneous metastasis of signet ring cell carcinoma in the form of multiple, asymptomatic, skin-colored, nodular lesions on his neck and chest.

Conclusions: Signet ring cell carcinoma is a rare type of adenocarcinoma, the primary site of which is the stomach. Moreover, the usual metastasis sites of the tumor are the lung and the liver. The timely diagnosis of such a malignant and aggressive tumor is possible by detecting the unusual presentations of cutaneous metastasis, which would result in offering timely interventions and saving patient's lives.
\end{abstract}

Keywords: Signet Ring Cell Carcinoma, Cutaneous Metastasis, Punch Biopsy

\section{Introduction}

Signet ring cell carcinoma is a rare form of highly malignant adenocarcinoma, with the prevalence rate of $<1 \%$. The most common site of the primary tumor is the stomach, and the secondary sites are breast, gall bladder, urinary bladder, and pancreas. Gastric cancer is the fifth most frequently diagnosed cancer and the third leading cause of cancer-related death worldwide. Despite a decrease in the prevalence of gastric cancer in recent decades, the prevalence of signet ring cell carcinoma in the stomach is constantly increasing in Asia, the United States, and Europe (1). Signet ring cell carcinomas are called so regarding their resemblance to signet ring cells, resulting from the formation of large vacuoles full of mucin displacing the nucleus to the periphery and forming a crescent-shaped nucleus. Signet ring cell adenocarcinomas are classified as "undifferentiated" and "diffuse" by Nakamura and Lauren, respectively (2). The common sites of metastasis are the liver and the lung. Skin metastasis is extremely rare, with the preva- lence rate of $0.3 \%$.

\section{Case Presentation}

A 30-year-old male was admitted to our hospital with chief complaints of anorexia and weight loss for six months, as well as chest pain for five days. He remarkably had the weight of $10 \mathrm{kgs}$ over the last six months. He was diagnosed with bilateral pleural effusion on chest x-ray, suggestive of bilateral blunting of costophrenic angles. He was treated for the same problem at a tertiary hospital.

On further examinations, the patient was cachexic, and pallor was noticed. Dermatological examination showed multiple asymptomatic skin-colored nodules with sizes ranging from 0.5 - 4 centimetres (3), some of which had coalesced together and distributed over the neck and the upper part of the chest (Figure 1). Few other lesions were discretely spread on the forehead, cheek, shoulders, and upper back (Figure 2) (4). On routine lab investigations, the results were as follows: Haemoglobin: $9.8 \mathrm{~g} / \mathrm{dL}$; Total 
leucocyte count: 11,300 per cubic millimetre; Differential leucocyte count: Neutrophils 83\%, lymphocytes17\%, and 0\% of eosinophil, basophil, and monocyte; and platelet count: 3.8 lakhs per microliter of blood.

The results of the renal function tests showed creatinine value of $0.7 \mathrm{mg} \%$ and urea levels of $28 \mathrm{mg} \%$; indicating normal levels.

Liver function test results were as follows: Total bilirubin: $0.9 \mathrm{mg} \%$, direct bilirubin: $0.3 \%$, indirect bilirubin: 0.6\%, SGOT levels: 22.45, SGPT levels: 29.78, and Alkaline phosphatase: 198 (all of which were in a normal range), total protein: $5.9 \mathrm{gm} \%$, albumin levels: $3.6 \mathrm{gm} / \mathrm{dl}$, globulin levels: $2.3 \mathrm{gm} / \mathrm{dL}$.

Pleural fluid analysis: Yellowish in appearance, nonturbid, red blood cell count: 130 cells $/ \mathrm{mm}^{3}$, white blood cell count: 400 cells $/ \mathrm{mm}^{3}$, Neutrophils 30\%, lymphocytes 70\%. Pleural fluid protein: $6.5 \mathrm{gm} \%$, and pleural fluid sugar: $80 \mathrm{mg} / \mathrm{dL}$. All experiments were suggestive of exudative pleural effusion according to Light's criteria (5) under malignant conditions.

A punch biopsy was taken from one of the nodules located on the upper part of the chest after obtaining the patient's consent. Biopsy revealed the infiltration of the dermis with islands of round to oval tumor cells surrounded by pools of intracellular mucin. The cells had hyperchromatic nuclei, some of which were eccentrically placed and compressed with abundant intracellular mucin, representing signet ring cells (6). The tumor islands surrounded collagenous stroma with focal infiltration by mononuclear cells, indicating metastatic signet ring cell carcinoma (Figures 3 and 4) (7). Immunohistochemistry was performed later, the results of which were positive for pan cytokeratin (8). Unfortunately, the patient expired a few days after being diagnosed with signet ring cell carcinoma.

\section{Discussion}

Signet ring cell carcinoma is a rare type of adenocarcinoma, the primary site of which is the stomach. Moreover, the usual metastasis sites of the tumour are the lung and the liver. The timely diagnosis of such a malignant and aggressive tumor is likely by detecting the unusual presentation of cutaneous metastasis (9), so that timely interventions can be provided to save lives of the patients by adequate surgical resection in the form of gastrectomy involving resection of atleast two thirds of the stomach with a D2 lymph node dissection (10). Many adjuvant and neoadjuvant therapies in the form of chemotherapy and radio- therapy have been suggested, however the future of curative treatment of signet ring cell carcinoma of the stomach remains challenging (11).

\section{Footnotes}

Authors' Contribution: Concepts, design, and definition of intellectual content, data analysis, literature review, manuscript preparation, manuscript editing, manuscript review, data collection, and guarantor: Malika Sharma, Umesh Bhoi, Shekhar Pradhan, Asha Khade, Sudarshan Gaurkar, Liza Borah.

Conflict of Interests: No conflict of interests.

Ethical Approval: Funding/ Support: None declared by the author

Funding/Support: The study received no funding, and the state hospital bore the cost of all investigations.

Informed Consent: The informed consent was obtained from the participants. 


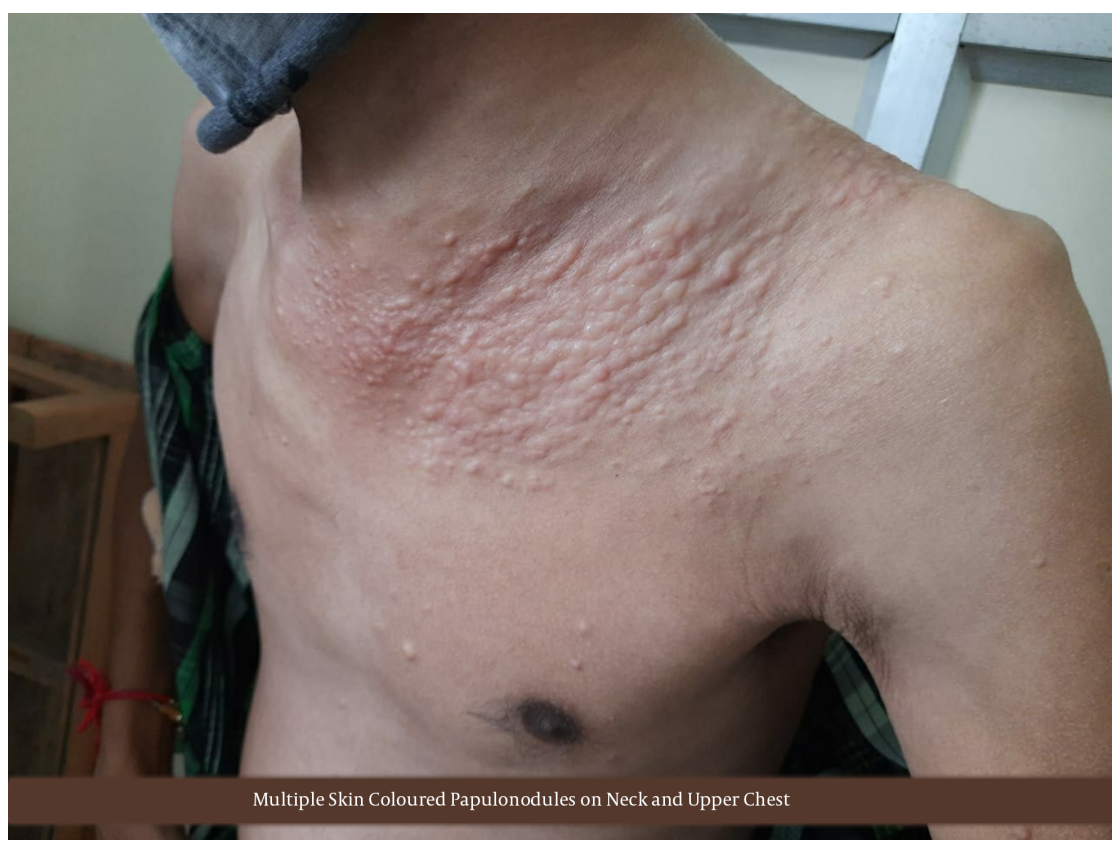

Figure 1. Multiple flesh-colored asymptomatic nodules on neck and upper chest

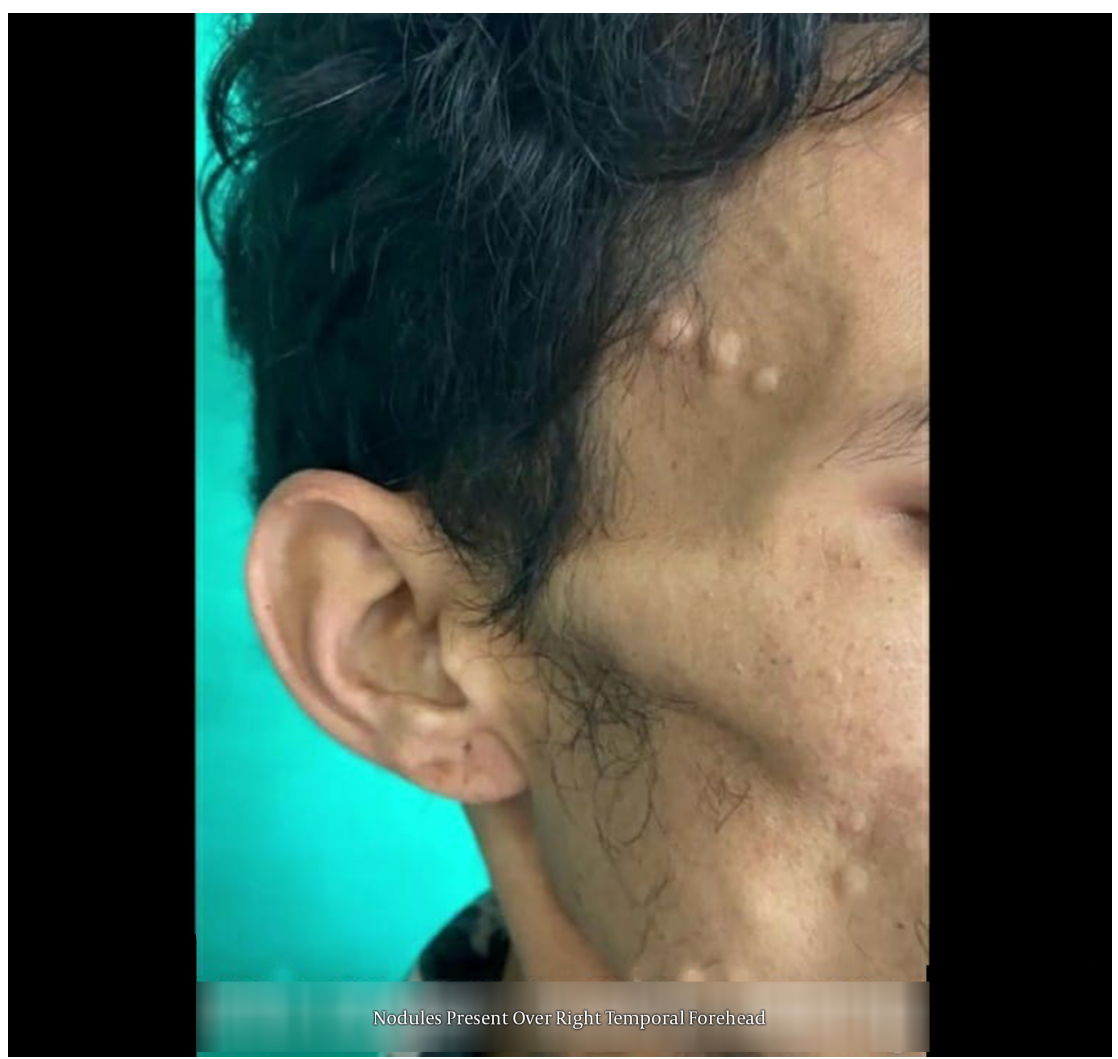




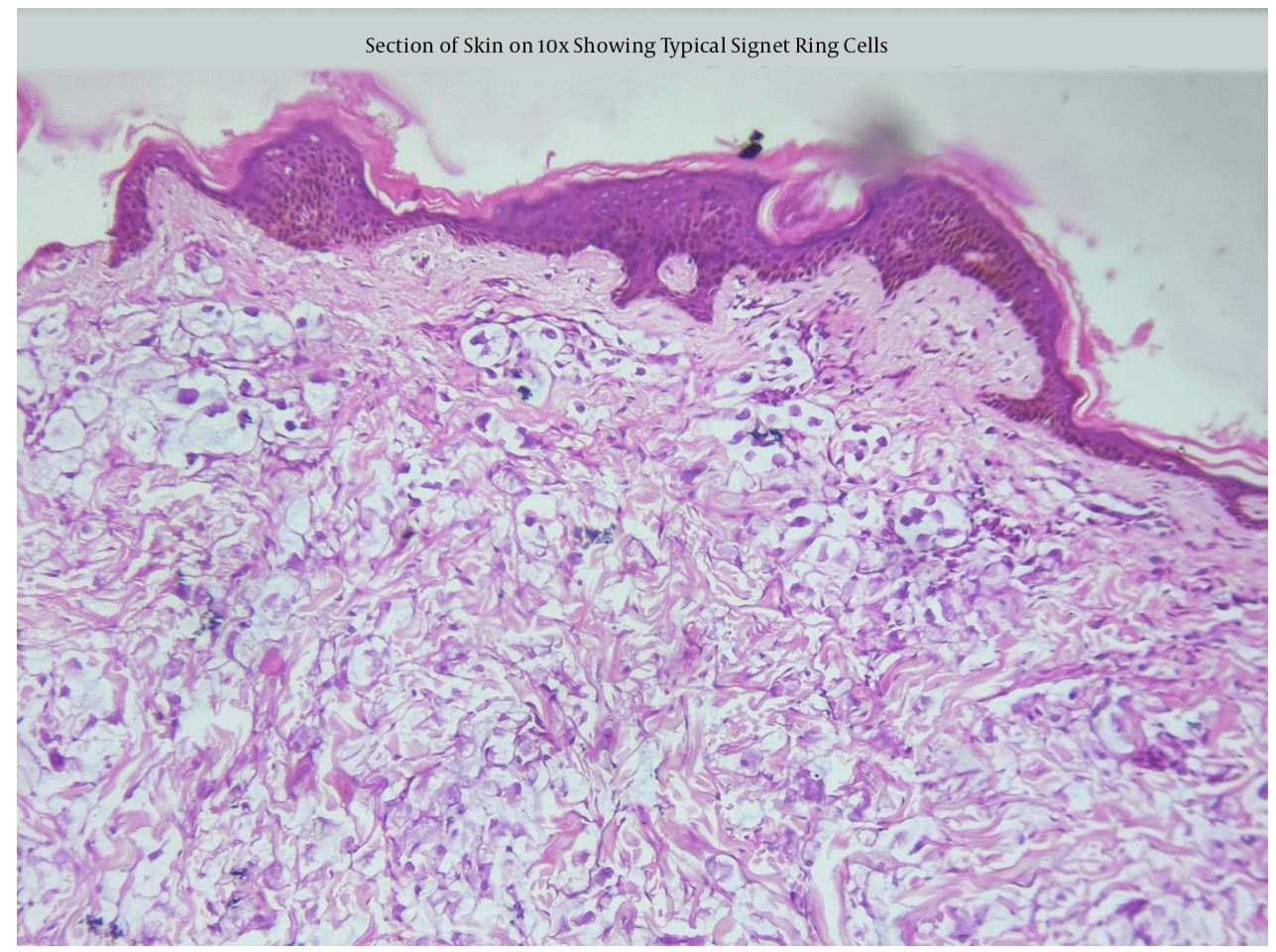

Figure 3. A skin section at 10x, presenting signet ring cells typically with flat compressed nucleus

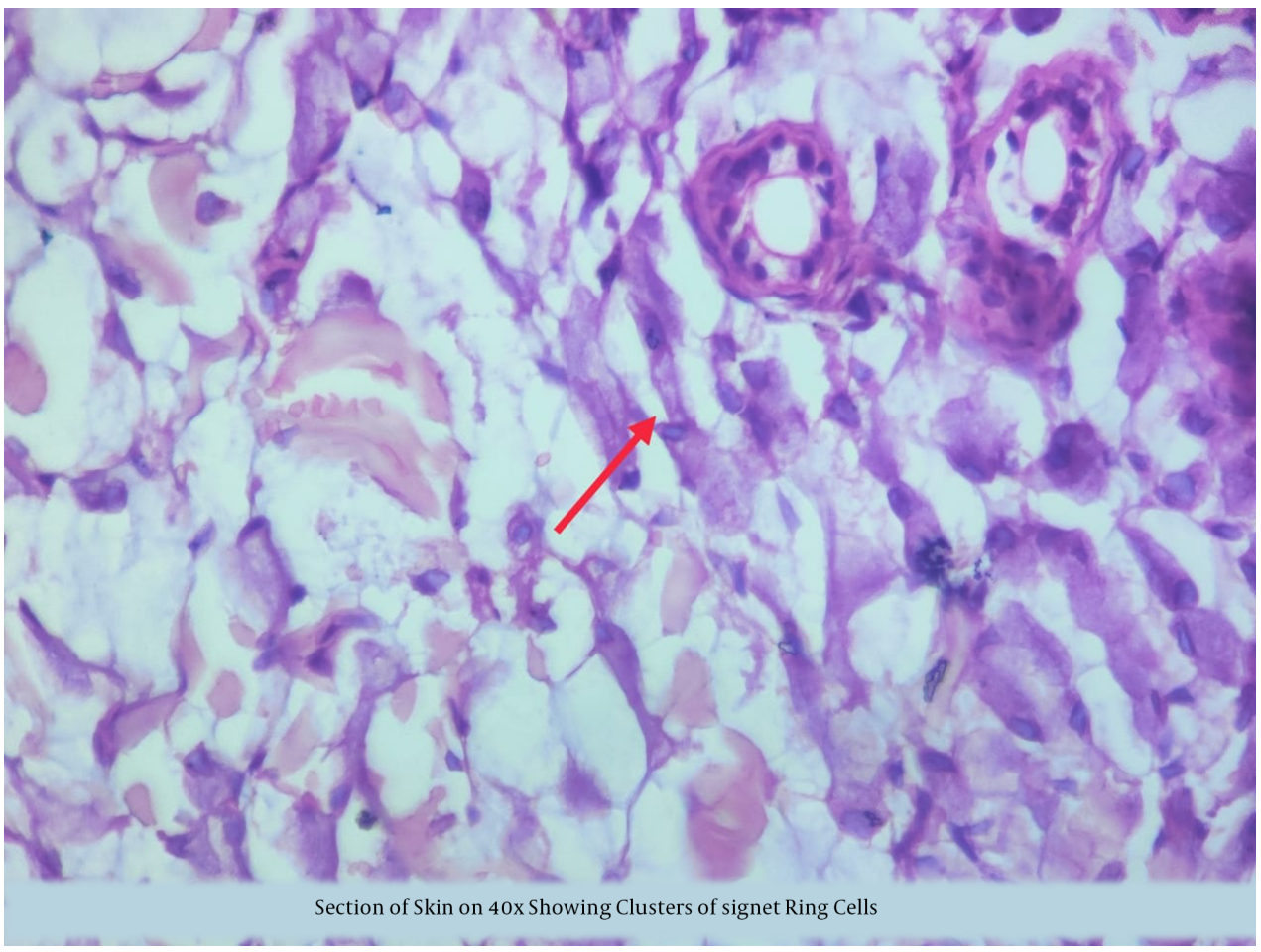

Figure 4. A skin section at 40x, presenting clusters of signet ring cells surrounding sweat and sebaceous glands 


\section{References}

1. Pernot S, Voron T, Perkins G, Lagorce-Pages C, Berger A, Taieb J. Signetring cell carcinoma of the stomach: Impact on prognosis and specific therapeutic challenge. World J Gastroenterol.2015;21(40):11428-38. doi: 10.3748/wjg.v21.i40.11428. [PubMed: 26523107]. [PubMed Central: PMC4616218].

2. Ma J, Shen H, Kapesa L, Zeng S. Lauren classification and individualized chemotherapy in gastric cancer. Oncol Lett. 2016;11(5):295964. doi: 10.3892/ol.2016.4337. [PubMed: 27123046]. [PubMed Central: PMC4840723].

3. Aneiros-Fernandez J, Husein-ElAhmed $\mathrm{H}$, Arias-Santiago S, Escobar Gómez-Villalva F, Nicolae A, O'Valle Ravassa F, et al. Cutaneous metastasis as first clinical manifestation of signet ring cell gastric carcinoma. Dermatology Online Journal. 2010;16(3). doi: $10.5070 / \mathrm{d} 38 \mathrm{~h} 84 \mathrm{j} 3 \mathrm{~d} 2$.

4. Brownstein MH, Helwig EB. Patterns of cutaneous metastasis. Arch Dermatol.1972;105(6):862-8. [PubMed: 5030236].

5. Light RW. Diagnostic principles in pleural disease. Eur Respir J. 1997;10(2):476-81. doi: 10.1183/09031936.97.10020476. [PubMed: 9042652].

6. Gunduz O, Emeksiz MC, Atasoy P, Kidir M, Yalcin S, Demirkan S. Signetring cells in the skin: A case of late-onset cutaneous metastasis of gas- tric carcinoma and a brief review of histological approach. Dermatol Reports. 2016;8(1):6819. doi: 10.4081/dr.2016.6819. [PubMed: 28326183]. [PubMed Central: PMC5225968].

7. Li C, Kim S, Lai JF, Hyung WJ, Choi WH, Choi SH, et al. Advanced gastric carcinoma with signet ring cell histology. Oncology. 2007;72(1-2):64-8. doi: 10.1159/000111096. [PubMed: 18004078].

8. Otsuji E, Yamaguchi T, Sawai K, Takahashi T. Characterization of signet ring cell carcinoma of the stomach.J Surg Oncol.1998;67(4):21620. doi:10.1002/(sici)1096-9098(199804)67:4<216::aid-jso2>3.0.co;2-b. [PubMed: 9579367].

9. Bertani E, Tamborini M, Veraldi S. Atypical cutaneous metastases from signet-ring cell gastric carcinoma. 3. 2nd ed. Skin Cancer; 1988.

10. Li Y, Zhu Z, Ma F, Xue L, Tian Y. Gastric signet ring cell carcinoma: Current management and future challenges. Cancer Manag Res. 2020;12:7973-81. doi: 10.2147/CMAR.S268032. [PubMed: 32943931]. [PubMed Central: PMC7478370].

11. Pernot S, Dubreuil O, Aparicio T, Le Malicot K, Tougeron D, Lepere C, et al. Efficacy of a docetaxel-5FU-oxaliplatin regimen (TEFOX) in first-line treatment of advanced gastric signet ring cell carcinoma: an AGEO multicentre study. Br J Cancer. 2018;119(4):424-8. doi: 10.1038/s41416018-0133-7. [PubMed: 29872148]. [PubMed Central: PMC6133962]. 